\title{
Blood Cadmium and Hyperuricemia in Adults with Special Reference to Sex Difference
}

\author{
Tomoyuki Kawada ${ }^{1}$ (i)
}

Received: 26 May 2021 / Accepted: 9 June 2021 / Published online: 17 June 2021

(c) The Author(s), under exclusive licence to Springer Science+Business Media, LLC, part of Springer Nature 2021

I read with great interest the published article in Biological Trace Element Research by Zeng et al. [1]. The authors evaluated the association between blood cadmium, serum uric acid levels, and hyperuricemia in subjects aged 19 and over, stratified by gender. The median blood cadmium was $0.27 \mu \mathrm{g} / \mathrm{L}$ in men and $0.33 \mu \mathrm{g} / \mathrm{L}$ in women. There was a nonlinear inverse relationship between hyperuricemia and blood cadmium among men, and there was a significant increase of hyperuricemia by cadmium exposure among women, presenting odds ratio (OR) $(95 \%$ confidence interval $[\mathrm{CI}])$ of 1.58 (1.08-2.31). Instead, there was no significant association between serum uric acid levels and blood cadmium regardless of sex. There was a sex difference on the association between blood cadmium and hyperuricemia. Blood cadmium reflects relatively recent cadmium exposure and the authors evaluated the risk of hyperuricemia in adults with low-level cadmium exposure. I have found a concern regarding their study by presenting a recent study, which was also cited by Zeng et al. [1].

Park and Kim [2] evaluated blood lead, mercury, cadmium, and serum uric acid, stratified by sex. They also observed lower geometric mean of blood cadmium in men relative to women, presenting 0.80 and $1.04 \mu \mathrm{g} / \mathrm{L}$, respectively. Logarithmic values of uric acid level had significant negative association with blood cadmium in women, and OR $(95 \% \mathrm{CI})$ of women with the highest quartiles of blood cadmium for hyperuricemia was $0.495(0.246-0.998)$. These data indicate that blood cadmium level was inversely associated with uric acid level and hyperuricemia in women. There was a discrepancy of the association between blood cadmium, serum uric acid levels, and hyperuricemia. The level of cadmium exposure is about threefold higher in this study, and I suspect that narrow ranges of blood cadmium

Tomoyuki Kawada

kawada@nms.ac.jp

1 Department of Hygiene and Public Health, Nippon Medical School, 1-1-5 Sendagi, Bunkyo-Ku, Tokyo 113-8602, Japan might have presented partial relationship, which is different from the relationship with wide ranges of blood cadmium. In addition, ethnic difference should be paid with caution. I am also afraid of the difference in specimen, because Zeng et al. described "serum cadmium" instead of whole blood cadmium. Furthermore, cadmium body burden can be ordinarily conducted by urinary cadmium concentration, which reflects long-term cadmium exposure [3].

Exposure to cadmium can occur through occupational exposure, smoking, and eating contaminated food such as vegetables and rice. In any case, prospective studies are recommended to verify the effect of cadmium exposure on subsequent risk of hyperuricemia and the mechanism of the association.

\section{Declarations}

Conflict of Interest The author declares no competing interests.

\section{References}

1. Zeng A, Li S, Zhou Y, Sun D (2021) Association between lowlevel blood cadmium exposure and hyperuricemia in the American general population: a cross-sectional Study. Biol Trace Elem Res. https://doi.org/10.1007/s12011-021-02700-7

2. Park J, Kim Y (2021) Associations of blood heavy metals with uric acid in the Korean general population: analysis of data from the 2016-2017 Korean National Health and Nutrition Examination Survey. Biol Trace Elem Res 199(1):102-112. https://doi.org/ 10.1007/s12011-020-02152-5

3. Buser MC, Ingber SZ, Raines N, Fowler DA, Scinicariello F (2016) Urinary and blood cadmium and lead and kidney function: NHANES 2007-2012. Int J Hyg Environ Health 219(3):261-267. https://doi.org/10.1016/j.ijheh.2016.01.005

Publisher's Note Springer Nature remains neutral with regard to jurisdictional claims in published maps and institutional affiliations. 